\title{
THE DETERIORATION OF ADMIXTURE CONCRETE IN A SULPHATE ENVIRONMENT
}

\author{
${ }^{\#}$ LEI JIANG*, DITAO NIU** \\ *College of Civil Engineering and Architecture, Anyang Normal University, Anyang, 455000, China \\ ${ }^{* *}$ College of Civil engineering, Xi'an University of Architecture and Technology, Xi'an, 710055, China \\ \#E-mail: djjianglei@126.com
}

Submitted November 17, 2018; accepted January 7, 2019

\begin{abstract}
Keywords: Concrete, Mineral admixtures, Sulphate attack, Drying-wetting cycles, Damage layer thickness
The deterioration mechanism of concrete with mineral admixtures subjected to drying-wetting cycles in a $10 \%$ sodium sulphate solution was studied. Plain concrete without fly ash addition, concrete with $10 \%, 20 \%$ and $30 \%$ fly ash addition, and a concrete with $20 \%$ fly ash and $30 \%$ slag addition were used. Through the experiment, the weight loss, the relative dynamic modulus of elastically (RDME), the compressive strength loss and the damage layer thickness $\left(H_{f}\right)$ of the concrete were measured. Furthermore, scanning electron microscopy, X-ray diffraction and thermal analysis were used to investigate the corrosion products of the concrete. The test results show that the ultrasonic velocity in the damage layer decreases and the $H_{f}$ of the concrete increases as the corrosion time grows, indicating that the deterioration degree of the concrete increases. There is a significant relationship between the RDME and the $H_{f}$ after $210 \mathrm{~d}$. The deterioration degree of the concrete decreases with an increase in the fly ash content. However, the sulphate resistance property of the concrete significantly decreases with $30 \%$ fly ash content. When mixed with $20 \%$ fly ash and $30 \%$ slag, the sulphate resistance property of the concrete is the best.
\end{abstract}

\section{INTRODUCTION}

Sulphate widely exists in the world; sulphate attack is one of the most aggressive environmental degradation effects that affect the durability and service life of concrete structures. The deterioration of concrete caused by a sulphate attack can manifest in the form of expansion and cracking of the concrete. Sometimes the expansion of the concrete may cause serious structural problems. A sulphate attack can also take the form of a progressive decrease in the strength and loss of mass due to loss of cohesiveness of the cement hydration products $[1,2]$.

For concrete in the fluctuating groundwater table splash and tidal zone, drying-wetting cycles can accelerate the deterioration of the concrete [3-5]. Based on the mechanism of the sulphate attack, the deterioration of the concrete in the sulphate environment is a process from outside to inside. The one-side non-destructive testing method can be used to detect the damage layer of the concrete, which allows for the valid prediction of the deterioration degree of the concrete. Naffa et al. [6] showed that it is possible to detect and characterise concrete cover degradation using a high-frequency ultrasound. Wang et al. [7, 8] suggested that ultrasonic penetration testing can be used to locate the interface between the solid and corroded concrete. Niu et al. [9] obtained that the damage to the concrete under a sulphate attack can be determined by using simple ultrasonic testing methods. According to the literature [10, 11], the $H_{\mathrm{f}}$ of the concrete exposed to a freeze-thaw environment could be detected based on ultrasonic detection methods.

Incorporation of mineral admixtures such as fly ash, slag and silica fume has often been used to improve the sulphate resistance property of concrete. The quantity of tricalcium silicate in cementitious materials decreases by using mineral admixtures in concrete. This method can partially consume calcium hydroxide through the pozzolanic reaction and reduce the formation of corrosion products [12-14]. However, the types and content of mineral admixture have different effects on the deterioration of the concrete. The deterioration mechanism of the concrete with mineral admixtures in a sulphate environment also needs further research.

The present study simulated a sulphate attack on concrete exposed to a sulphate solution under cyclic environmental conditions, the drying state was natural drying in the air, which is more relevant to the real environment. The weight loss, the RDME change, the compressive strength loss and the $H_{\mathrm{f}}$ of the concrete with the addition of different mineral admixtures were conducted. Furthermore, the corrosion products and the damage mechanism of the concrete were discussed by using microscopic tests. 


\section{EXPERIMENTAL}

\section{Materials}

A Chinese standard ordinary Portland cement (OPC) of PO 42.5R produced by the cement factory of Tongchuan was used. The slag was produced by the Powder Engineering Research Institute in Xi'an University of Architecture and Technology. Grade II fly ash from the Weihe power station, river sand with a fineness modulus of 2.69 and coarse aggregate of crushed basalt stone with a diameter of $5 \mathrm{~mm}$ to $16 \mathrm{~mm}$ were used in the test. A naphthalene-type superplasticiser was used, and the dosage was adjusted to keep the slump of the fresh mixed concrete in the range of $50 \mathrm{~mm}$ to $120 \mathrm{~mm}$. Tap water was used as the mix water. The chemical composition of the cement, fly ash and slag is shown in Table 1.

Table 1. The chemical composition of the OPC and fly ash.

\begin{tabular}{lrrrrll}
\hline $\begin{array}{l}\text { Constituent } \\
\text { (wt. \%) }\end{array}$ & $\mathrm{SiO}_{2}$ & $\mathrm{Al}_{2} \mathrm{O}_{3}$ & $\mathrm{CaO}$ & $\mathrm{MgO}$ & $\mathrm{SO}_{3}$ & $\mathrm{Fe}_{2} \mathrm{O}_{3}$ \\
\hline OPC & 21.66 & 5.13 & 64.37 & 1.06 & 2.03 & 5.25 \\
Fly ash & 49.02 & 31.56 & 4.88 & 0.83 & 1.2 & 6.97 \\
Slag & 33.15 & 12.91 & 40.00 & 6.75 & 0.12 & 2.80 \\
\hline
\end{tabular}

Preparation of the sample

In this experiment, the water binder ratio was 0.45 and the sodium sulphate solution with a concentration (by mass) of $10 \%$ was used. Five different binders, namely $100 \%$ OPC, $90 \%$ OPC $+10 \%$ fly ash, $80 \%$ OPC $+20 \%$ fly ash, $70 \%$ OPC $+30 \%$ fly ash, and $50 \%$ OPC $+20 \%$ fly ash $+30 \%$ slag (denoted as F0 \%, F10 \%, F20 \%, F30 \% and F20 \% + S30 \%, respectively) were used in this study. All specimens were demoulded after $24 \mathrm{~h}$ of casting and cured in a condition of $20 \pm 3{ }^{\circ} \mathrm{C}$ and $95 \%$ relative humidity until the age of testing. The mixture proportion of the concrete is given in Table 2 .

Test method

\section{Test procedure}

At the age of 90 days curing, the concrete specimens were exposed to the sulphate solution under drying-wetting cycles up to 360 days. One wet-dry cycle lasted 15 days. First, the specimens were continuously immersed in the test solution for 7 days, and then were moved into the air to dry naturally for another 8 days. Specimens of $100 \times 100 \times 400 \mathrm{~mm}$ prisms were used for the study of the weight loss, the RDME and the $H_{\mathrm{f}}$ of concrete. Specimens of $100 \times 100 \times 100 \mathrm{~mm}$ cubes were used to study the compressive strength loss and the analysis of the microstructure of the concrete. According to the test procedure, the deterioration of the specimens was investigated by determining the RDME, weight loss and compressive strength loss.

\section{Weight loss}

According to the GB/T50081 method [15], Equation 1 was used to calculate the weight loss:

$$
\Delta W_{\mathrm{n}}=\left[\left(W_{0}-W_{\mathrm{n}}\right) / W_{0}\right] \times 100
$$

where $\Delta W_{\mathrm{n}}$ is the weight loss of the specimens after every 30 days of exposure (\%), $W_{0}$ is the average weight of the concrete specimens before the sulphate attack $(\mathrm{kg})$ and $W_{\mathrm{n}}$ is the average weight of the concrete specimens after every 30 days of exposure in the sulphate solutions $(\mathrm{kg})$. RDME loss

The dynamic modulus of elasticity $\left(E_{\mathrm{d}}\right)$ was determined by Equation 2 [16]. The RDME was the ratio of the $E_{\mathrm{d}}$ value to the initial $E_{\mathrm{d}}$ value after every 30 days of exposure, which was determined by Equation 3.

$$
\begin{gathered}
E_{\mathrm{d}}=\frac{(1+v)(1-2 v) \rho V^{2}}{1-v} \\
R D M E=\frac{E_{\mathrm{dn}}}{E_{\mathrm{d} 0}}=\frac{V_{\mathrm{n}}^{2}}{V_{0}^{2}}
\end{gathered}
$$

where $V$ is the ultrasonic speed $\left(\mathrm{m} \cdot \mathrm{s}^{-1}\right), E_{\mathrm{d} 0}$ is the dynamic modulus of elasticity of the concrete before the sulphate attack $(\mathrm{GPa}), E_{\mathrm{dn}}$ is the dynamic modulus of elasticity of the concrete after every 30 days of exposure (GPa), $\rho$ is the density of the specimen $\left(\mathrm{kg} \cdot \mathrm{m}^{-3}\right)$ and $v$ is Poisson's ratio.

\section{Compressive strength}

The measurement of the compressive strength property was conducted according to the GB/T50081 [17] method. Equation 4 was used to calculate the compressive strength:

$$
f_{\text {cc }}=F / A
$$

where $f_{\mathrm{cc}}$ is the compressive strength (MPa), $F$ is the maximum load $(\mathrm{N})$ and $A$ is the area of the cube loading face $\left(\mathrm{mm}^{2}\right)$.

Table 2. The mix proportion of the concrete.

\begin{tabular}{lcccccccc}
\hline NO. & $\begin{array}{c}\text { Water-binder } \\
\text { ratio }\end{array}$ & $\begin{array}{c}\text { Cement } \\
\left(\mathrm{kg} \cdot \mathrm{m}^{-3}\right)\end{array}$ & $\begin{array}{c}\text { Fly ash } \\
\left(\mathrm{kg} \cdot \mathrm{m}^{-3}\right)\end{array}$ & $\begin{array}{c}\text { Slag } \\
\left(\mathrm{kg} \cdot \mathrm{m}^{-3}\right)\end{array}$ & $\begin{array}{c}\text { Sand } \\
\left(\mathrm{kg} \cdot \mathrm{m}^{-3}\right)\end{array}$ & $\begin{array}{c}\text { Aggregate } \\
\left(\mathrm{kg} \cdot \mathrm{m}^{-3}\right)\end{array}$ & $\begin{array}{c}\text { Water } \\
\left(\mathrm{kg} \cdot \mathrm{m}^{-3}\right)\end{array}$ & $\begin{array}{c}\text { Superplasticiser } \\
(\%)\end{array}$ \\
\hline F0 \% & 0.45 & 355 & - & - & 585 & 1300 & 160 & 0.5 \\
F10\% & 0.45 & 319 & 36 & - & 585 & 1300 & 160 & 0.5 \\
F20\% & 0.45 & 285 & 70 & - & 585 & 1300 & 160 & 0.5 \\
F30 \% & 0.45 & 249 & 106 & - & 585 & 1300 & 160 & 0.5 \\
F20 \% + S30 \% & 0.45 & 178 & 35 & 142 & 585 & 1300 & 160 & 0.5 \\
\hline
\end{tabular}




\section{Damage layer thickness}

The $H_{\mathrm{f}}$ is detected by using a high accuracy nonmetal ultrasonic analyser according to CECS 21:2000 [18] and literature [19]. The prism-side of a $100 \times 400 \mathrm{~mm}$ prism was selected as the test surface, as shown in Figure 1. The transmitting transducer $A$ is placed on the surface, and then a receiving transducer $B$ moves along the concrete surface to record the corresponding time of the sound propagation. The test distance $l$ between $A$ and $B$ is $50 \mathrm{~mm}, 75 \mathrm{~mm}, 100 \mathrm{~mm}, 150 \mathrm{~mm}, 200 \mathrm{~mm}$ and $250 \mathrm{~mm}$, respectively.

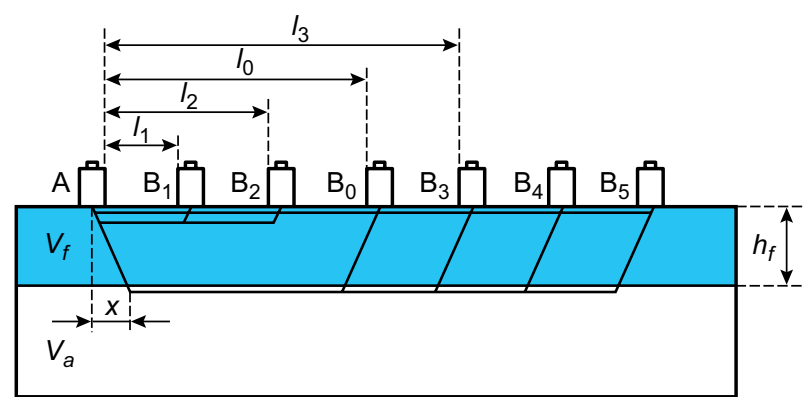

Figure 1. Setting the transducer.

At first, the receiving transducer $B$ close to the transmitter will only sense the top layer (the damaged layer of the concrete), but as the distance increases, the influence from the lower layer (the sound concrete) is felt. When the distance between the two transducers reaches a certain range $l_{0}$, the ultrasonic propagation time from $A$ to $B$ through the damage layer and the sound concrete is equal to the time propagated only in the damaged layer as shown in Figure 1. These are:

$$
\begin{gathered}
\frac{l_{0}}{V_{\mathrm{f}}}=\frac{2 \sqrt{h_{\mathrm{f}}^{2}+x^{2}}}{V_{\mathrm{f}}}+\frac{l_{0}-2 x}{V_{\mathrm{a}}} \\
H_{\mathrm{f}}=\frac{l_{0}}{2} \sqrt{\frac{V_{\mathrm{a}}-V_{\mathrm{f}}}{V_{\mathrm{a}}+V_{\mathrm{f}}}}
\end{gathered}
$$

where $x$ is the horizontal projection of the ultrasonic propagation path through the damaged layer $(\mathrm{mm}), V_{f}$ is the ultrasonic velocity in the damaged layer $\left(\mathrm{km} \cdot \mathrm{s}^{-1}\right) ; V_{a}$ is the ultrasonic velocity in the sound concrete $\mathrm{km} \cdot \mathrm{s}^{-1}$ ), $l_{0}$ is the distance from $A$ and $B$ when the ultrasonic pulse hits the interface between the damaged layer and the sound concrete $(\mathrm{mm})$.

The experimental results are plotted in a time vs. distance plot, which will be a straight line similar to Figure 2. It is shown that $l_{0}$ is the intersection of the two straight lines. The regression equations of $l-s$ in the damaged layer and in the sound concrete, by using the linear regression method, are as follows:

$$
\begin{aligned}
& l_{\mathrm{f}}=A_{\mathrm{f}}+V_{\mathrm{f}} t_{\mathrm{f}} \\
& l_{\mathrm{a}}=A_{\mathrm{a}}+V_{\mathrm{a}} t_{\mathrm{a}}
\end{aligned}
$$

where $l_{\mathrm{f}}$ is the distance before $l_{0}$ in Figure 2 , such as $l_{1}$ and $l_{2}(\mathrm{~mm}) ; l_{\mathrm{a}}$ is the distance after $l_{0}$, such as $l_{3}, l_{4}$ and $l_{5}(\mathrm{~mm}) ; t_{\mathrm{f}}$ is the time corresponding to $l_{\mathrm{f}}$ before $l_{0}$, such as $t_{1}$ and $t_{2}(\mu \mathrm{s}) ; t_{\mathrm{a}}$ is the time corresponding to $l_{\mathrm{a}}$ after $l_{0}$, such as $t_{3}, t_{4}$ and $t_{5}(\mu \mathrm{s}) ; A_{\mathrm{f}}$ and $A_{\mathrm{a}}$ are the intercept of the two lines, respectively; $V_{\mathrm{f}}$ and $V_{\mathrm{a}}$ are the slope of the two lines, respectively.

Therefore, $l_{0}$ can be written as

$$
l_{0}=\frac{A_{1} V_{\mathrm{a}}-A_{2} V_{\mathrm{f}}}{V_{\mathrm{a}}-V_{\mathrm{f}}}
$$

and $H_{\mathrm{f}}$ can be calculated by Equation 6 .

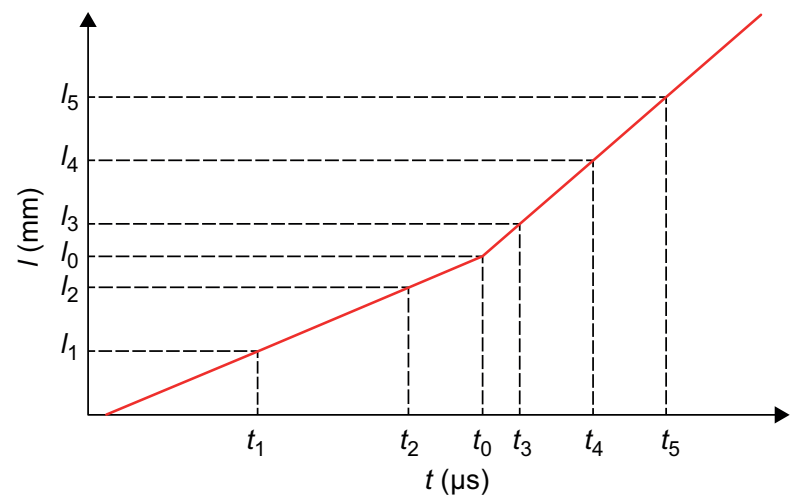

Figure 2. The relationship of the travel time and the test distance.

\section{Characterisation of the sample}

To identify the products formed by the sulphate attack, a scanning electron microscopy (SEM) equipped with an energy dispersive spectroscopy (EDS) detector, and X-ray diffraction (XRD) $(\mathrm{Cu}-\mathrm{K} \alpha)$ were used. In addition, thermogravimetric analysis (TG) and differential scanning calorimetry (DSC) was also used to analyse the corrosion products.

\section{RESULTS AND DISCUSSION}

The weight loss of the concrete

As can be seen from Figure 3, the weight loss of the concrete specimens exposed to a sulphate attack and drying-wetting cycles exhibits three distinct stages: a decreased stage, a steady stage and an increased stage. The weight loss for all the specimens is less than $1 \%$ after $360 \mathrm{~d}$. The weight loss of F20\% is seen to be less than those of F10 \% and F30\%. When exposed to 300 days, the weight loss of F30\% is higher than that of F10 \%. Compared to the concrete by adding the single fly ash, the weight loss of F $20 \%+$ S $30 \%$ presents a minimum increase. The test results also show that the weight loss of F0 \% is inconspicuous compared with that of F $20 \%+\mathrm{S} 30 \%$. Moreover, the weight loss of F0 \% is significantly lower than that of the concrete by mixing in the fly ash. 


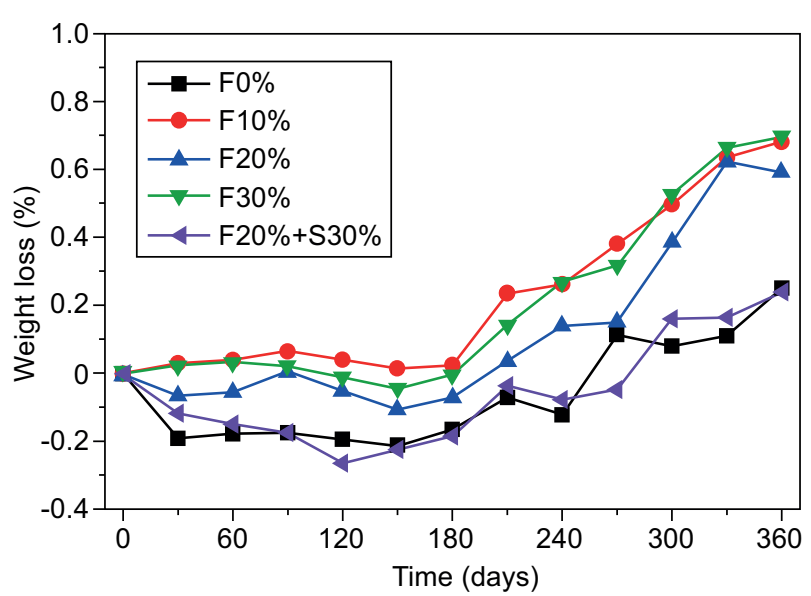

Figure 3. The weight loss of the concrete.

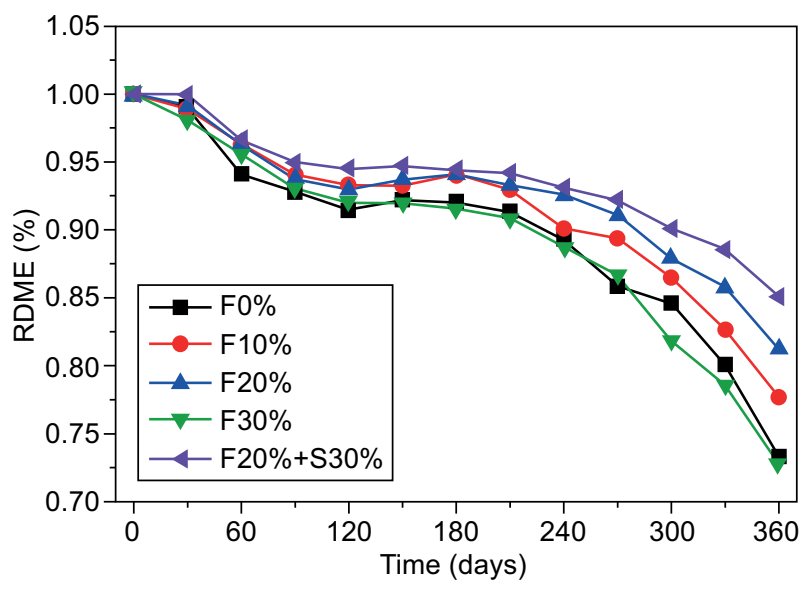

Figure 4. The RDME of the concrete.

The RDME of the concrete

As can be seen from Figure 4, the behaviour of the RDME of the concrete exposed to the sulphate solution under the drying-wetting cycles also exhibits three distinct periods: a decreased period, a steady period, and an accelerating decreased period. After 360 days, the RDME of F0 \%, F20 \% and F30 \% are $22.3 \%$, $18.8 \%$ and $27.2 \%$, respectively. The deterioration of the concrete is seen to increase with an increase in the fly ash content. However, the sulphate resistance property of the concrete is significantly decreased with the addition of $30 \%$ fly ash. The degradation rate of $\mathrm{F} 30 \%$ becomes much faster after 270 days compared with F0 \%. The concrete with $30 \%$ fly ash did not achieved a greater resistance under the sulphate attack. The RDME of $\mathrm{F} 20 \%+\mathrm{S} 30 \%$ decreases slowly in period III. It is shown that $\mathrm{F} 20 \%+\mathrm{S} 30 \%$ has the best performance in terms of the resistance of the concrete in the sulphate environment. The reason is that two kinds of mineral admixtures reasonably added and with the proper amount of water reducing the admixture is used to refine the pore structure. The compactness of the concrete is obviously improved, thus lowering the diffusion coefficient of the sulphate ions under the drying-wetting cycles.
The compressive strength of the concrete

Figure 5 shows the results of the compressive strength change of the concrete exposed to the sulphate solution. The compressive strength loss exhibits the following three periods: an increased period, a decreased period and an accelerating decreased period. As can be seen from Figure 5, the compressive strength of F0 \%, F20 \% and F30 \% decreased by $14.8 \%, 12.7 \%$ and $16.6 \%$ after 360 days, respectively. The compressive strength loss of the concrete is seen to increase with an increase in the fly ash content. The test results also show that the compressive strength loss of F0 \% is $16.2 \%$, indicating the degradation rate is lower than that of F30 \%. However, the compressive strength loss of F $20 \%$ $+\mathrm{S} 30 \%$ presents a minimum decrease of only by $9.7 \%$.

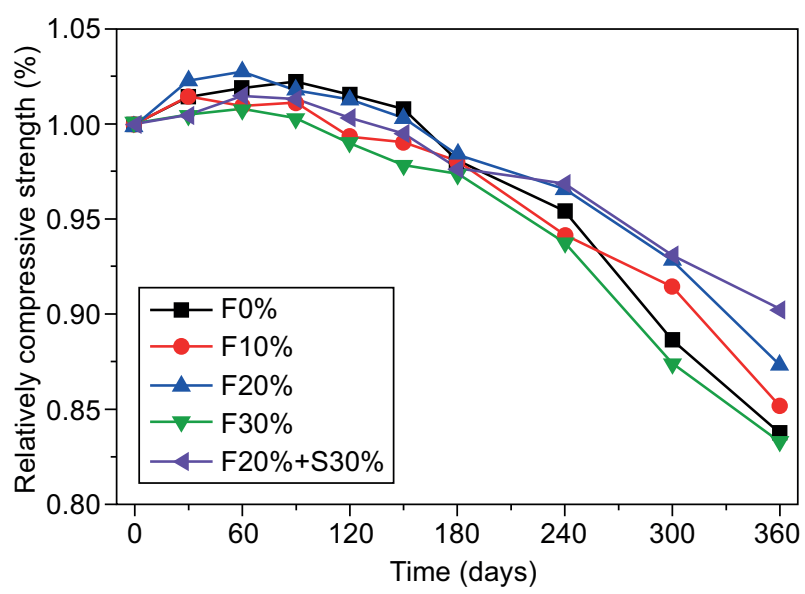

Figure 5. The relative compressive strength of the concrete.

The damaged layer of the concrete

The damaged layer of the concrete is not obvious at the beginning of the corrosion time. As the damage degree increases, it could be accurately calculated after 210 days in the test. The results agree with those suggested by Zhang et al [20], which showed that a larger error was observed for ultrasonic penetration testing when the $H_{\mathrm{f}}$ was small. The temporal variation of the $V_{\mathrm{f}}$ and the $H_{\mathrm{f}}$ are given in Figure 6 and Figure 7, respectively.

As can be seen from Figure 6, the decrease rate of $V_{\mathrm{f}}$ is seen to reduce with an increase in the fly ash content. But the decrease rate of $V_{\mathrm{f}}$ is considerably increased when the fly ash content reached $30 \%$. The change in $V_{\mathrm{f}}$ of $\mathrm{F} 10 \%$ is inconspicuous compared with that of $\mathrm{F} 30 \%$. However, the $V_{\mathrm{f}}$ of $\mathrm{F} 30 \%$ is lower than that of $\mathrm{F} 10 \%$ after 300 days. The $V_{\mathrm{f}}$ of $\mathrm{F} 20 \%+\mathrm{S} 30 \%$ presented the slowest reduction, it only decreased by $9.7 \%$.

As seen from Figure 7, the $H_{\mathrm{f}}$ increases with an increase in the corrosion time, which exhibits the opposite trend compared with $V_{\mathrm{f}}$. The results for the $H_{\mathrm{f}}$ change indicate a dependence on the fly ash content. The $H_{\mathrm{f}}$ decreases when the appropriate amount of fly ash content is used. But the $H_{\mathrm{f}}$ is largest when the content reaches 
$30 \%$, indicating that $\mathrm{F} 30 \%$ covers the most aggressive corrosion. When the $H_{\mathrm{f}}$ of the concrete is thicker and the $V_{\mathrm{f}}$ is lower, indicating that the compactness reduces and the deterioration degree of concrete increases. The results are in a good agreement with what was obtained in the literature $[10,20]$, which showed that an increase in $H_{\mathrm{f}}$ reduces the density of the concrete when exposed to a sulphate attack or freeze-thaw cycles.

Figure 8 shows the relationship between the RDME

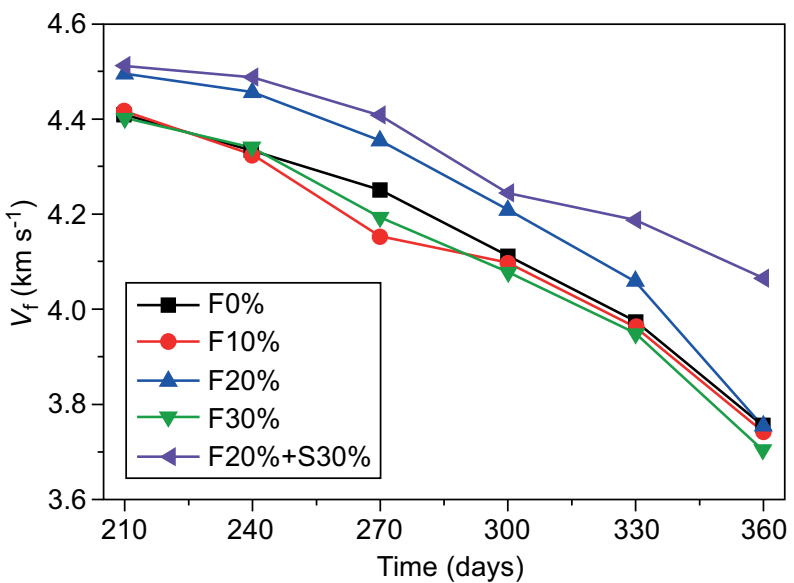

Figure 6. The $V_{\mathrm{f}}$ of the concrete.

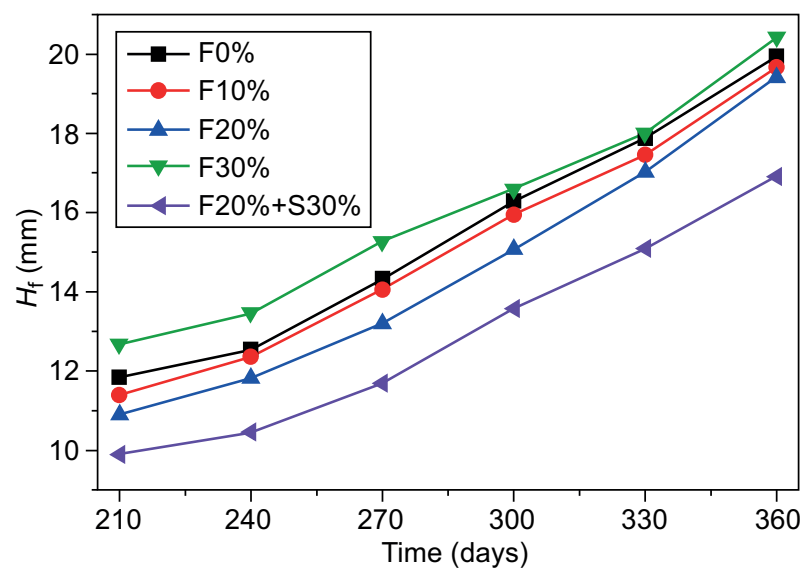

Figure 7. The $H_{\mathrm{f}}$ of the concrete.

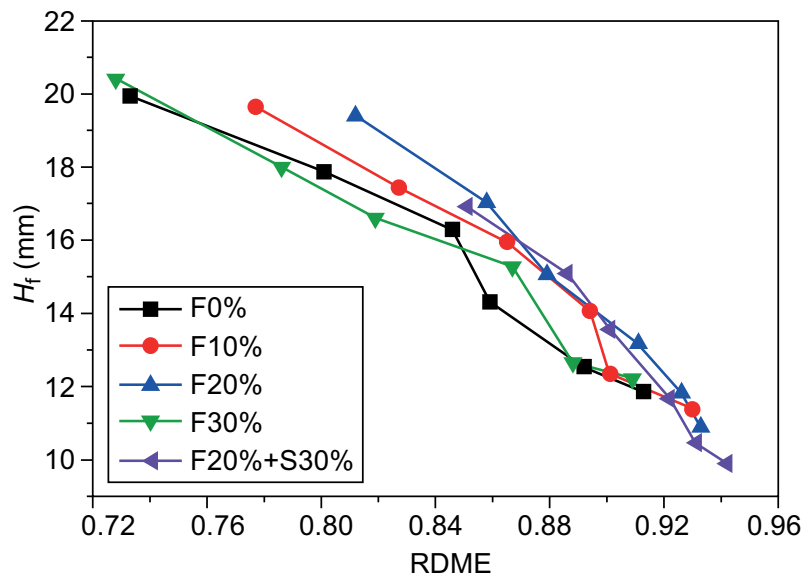

Figure 8. The relationship between the RDME and $H_{\mathrm{f}}$. and $H_{\mathrm{f}}$ of the concrete. It is shown that the temporal variation of $H_{\mathrm{f}}$ is in good agreement with the RDME after 210 days. There is a significant relationship between them. Obviously, the $H_{\mathrm{f}}$ of the concrete increases with a reduction in the RDME, indicating that the damage to the concrete increases. Therefore, the deterioration degree of the concrete could be estimated effectively by measuring the $H_{\mathrm{f}}$.

\section{The microstructures of the concrete}

Figure 9 shows the microstructure observation of the concrete under a sulphate attack and drying-wetting cycles. As shown in Figure 9a, needle-like crystals can be observed in the concrete pores. As the corrosion time grows, the amount of needle crystals continuously increases. The pores are almost completely filled up by needle-like corrosion products as shown in Figures $9 \mathrm{~b}$ and $9 \mathrm{c}$. Moreover, the microcracks in the pores can be clearly observed from the micrographs. The EDS spectra showed that the needle crystals consist of the elements $\mathrm{Al}, \mathrm{Si}, \mathrm{S}$ and $\mathrm{Ca}$, which indicated that the needle crystals are ettringite (Figure 9d).

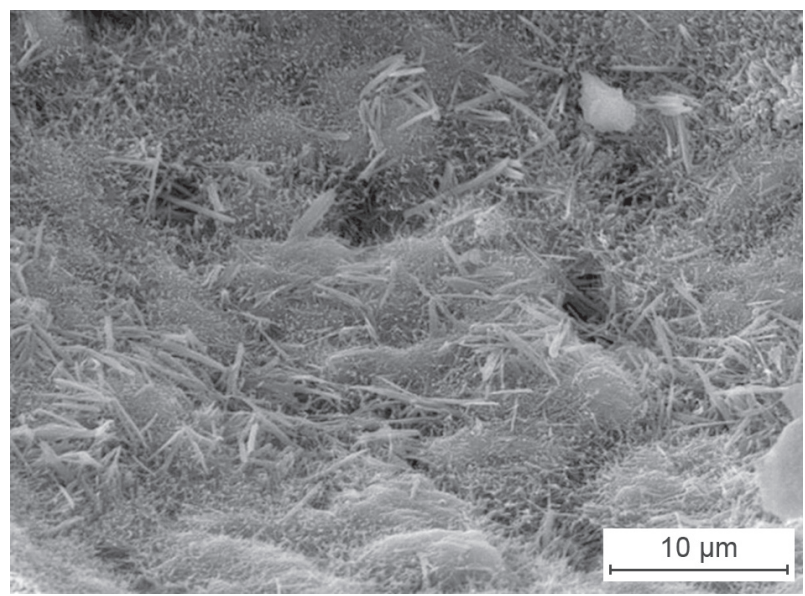

a) SEM micrograph

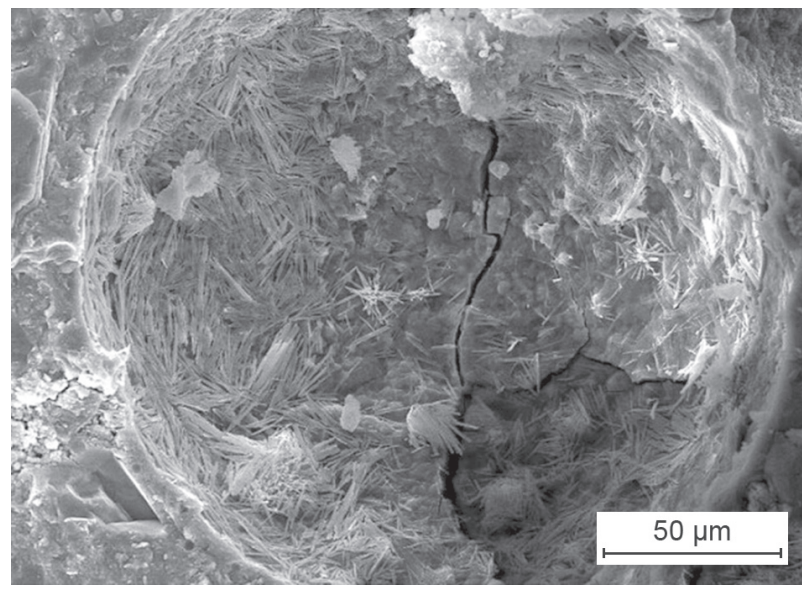

b) SEM micrograph

Figure 9. The SEM micrographs $(\mathrm{a}, \mathrm{b})$ of the needle crystals in the concrete. (Continue on next page) 
As shown in Figure 10a, short columnar crystals can be observed in the interface transition zone between the paste and the aggregate in the concrete specimens. The EDS spectra indicated that these crystals are gypsum, which detected the elements $\mathrm{Ca}$ and $\mathrm{S}$ (Figure 10b). When the expanding pressure generated by the ettringite and gypsum exceeds the tensile strength of the concrete, cracks occur.

In the test process, some petals shape crystals can be observed by using SEM as shown in Figure 11a. It was confirmed to be thenardite by using EDS (Figure 11b). The results show that the concrete specimens are attacked

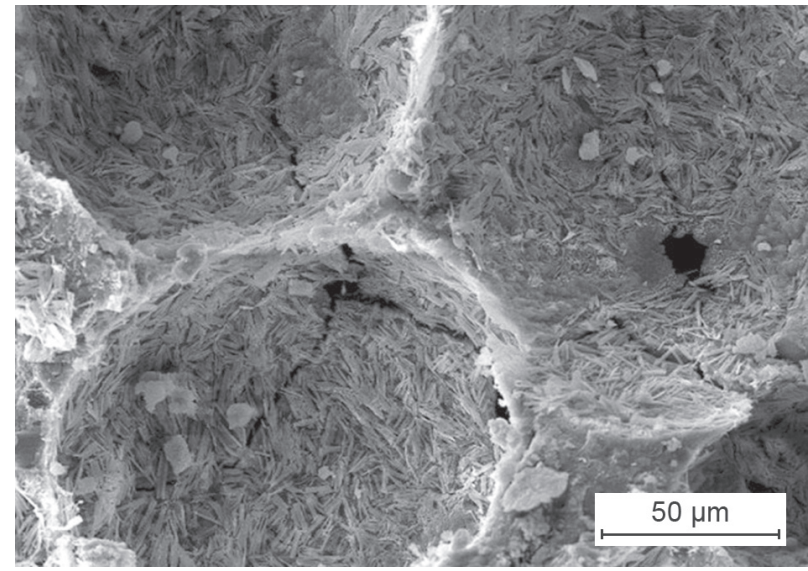

c) SEM micrograph

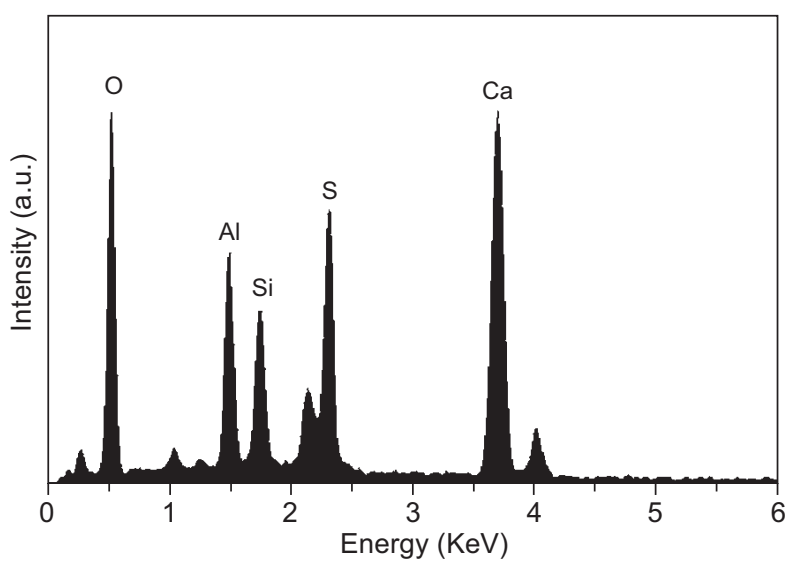

d) EDS spectrum

Figure 9. The SEM micrographs (c) and EDS spectrum (d) of the needle crystals in the concrete.

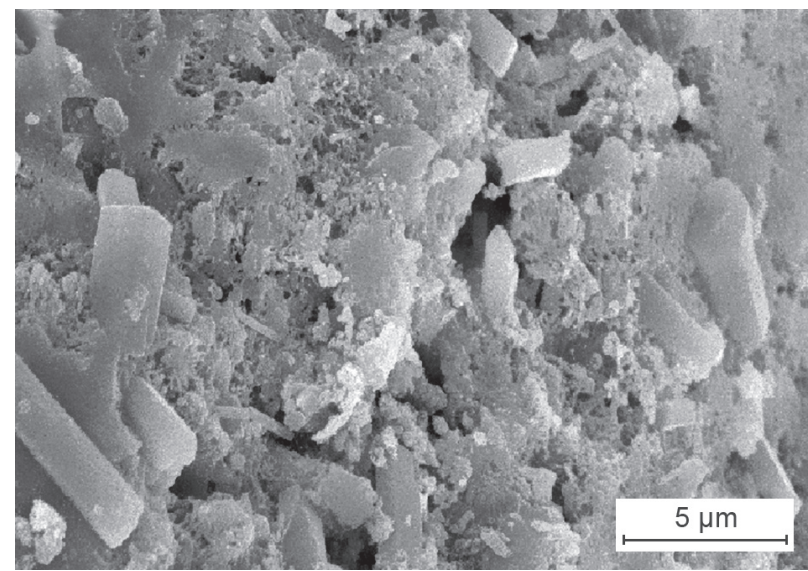

a) SEM micrograph

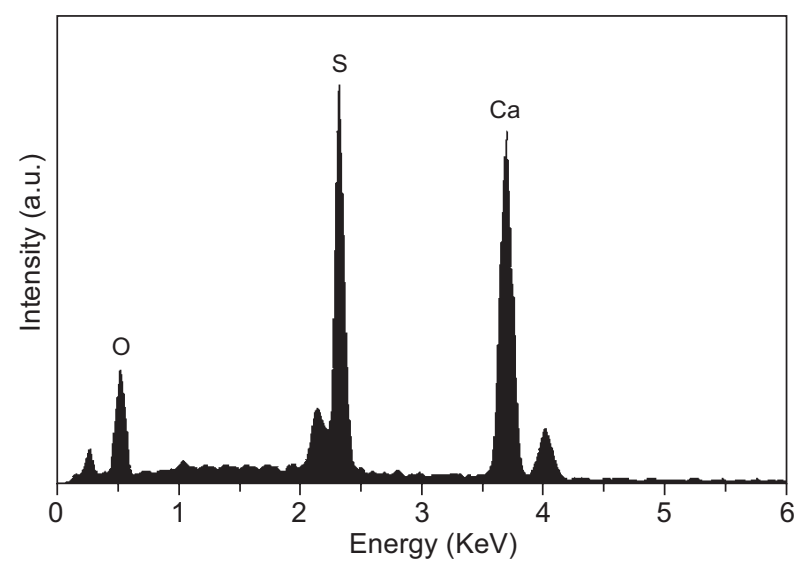

b) EDS spectrum

Figure 10. The SEM micrograph (a) and EDS spectrum (b) of the short columnar crystals in the concrete.

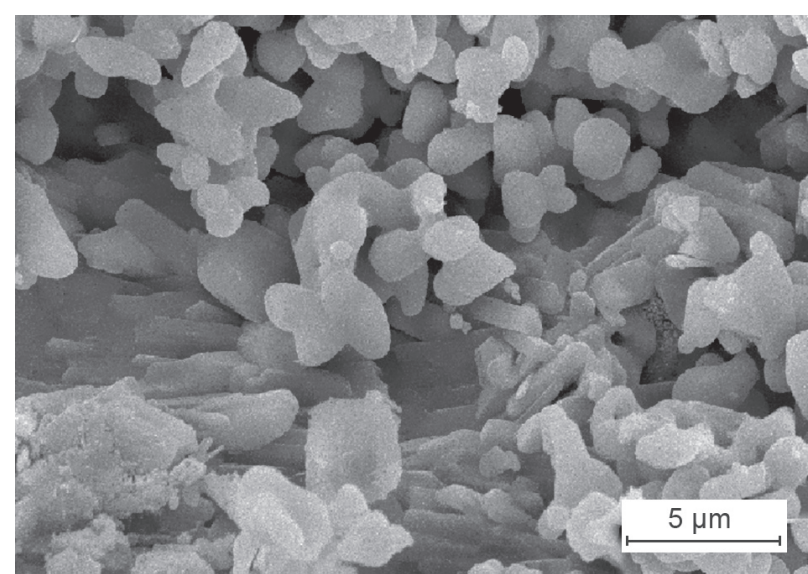

a) SEM micrograph

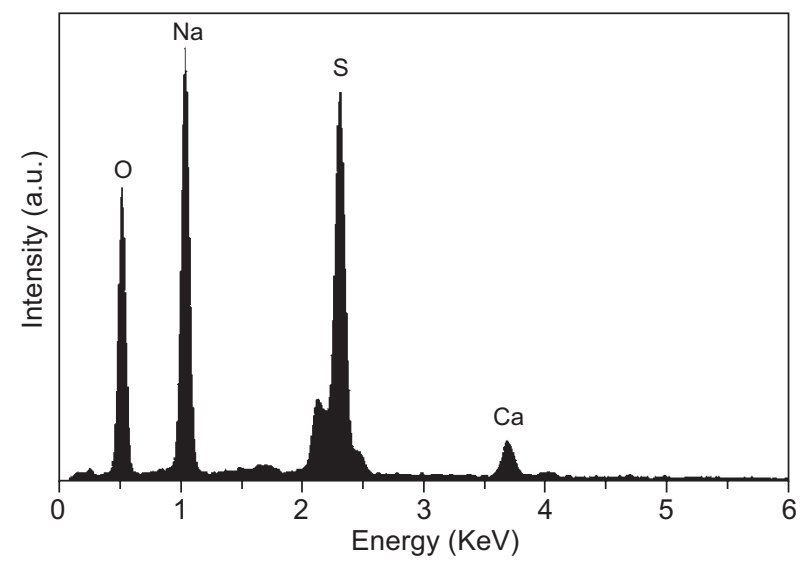

b) EDS spectrum

Figure 11. The SEM micrographs (a) and EDS spectrum (b) of the petal shaped crystals in the concrete. 
by corrosion products in the sodium sulphate solution during the wetting cycles. Furthermore, the concrete specimens also suffer from the crystallisation pressure of the thenardite crystals during the drying cycles.

\section{$\mathrm{XRD}$ analysis}

Figure 12 shows the XRD patterns of F20 \% under a sulphate attack and drying-wetting cycles. The results show that the peaks selected for the qualitative analysis of these phases are ettringite at $9.06^{\circ} 2 \theta$, gypsum at $15.86^{\circ} 2 \theta$, calcium hydroxide at $18.02^{\circ} 2 \theta$, quartz at $20.82^{\circ} 2 \theta$ and calcium carbonate at $29.36^{\circ} 2 \theta$. In these diagrams, quartz is mainly formed by the composition of the sand. Calcium carbonate is formed by the carbonisation reaction in the atmospheric environment during the dying cycles. The ettringite and gypsum peaks in the concrete are strong. This phenomenon demonstrates that they are the main corrosion products. Obviously, the concentrations of gypsum and ettringite increase with the corrosion time, and the content of gypsum in the concrete is less than that of ettringite in the test. Moreover, the concentration of calcium hydroxide gradually decreases along with the corrosion time growth.

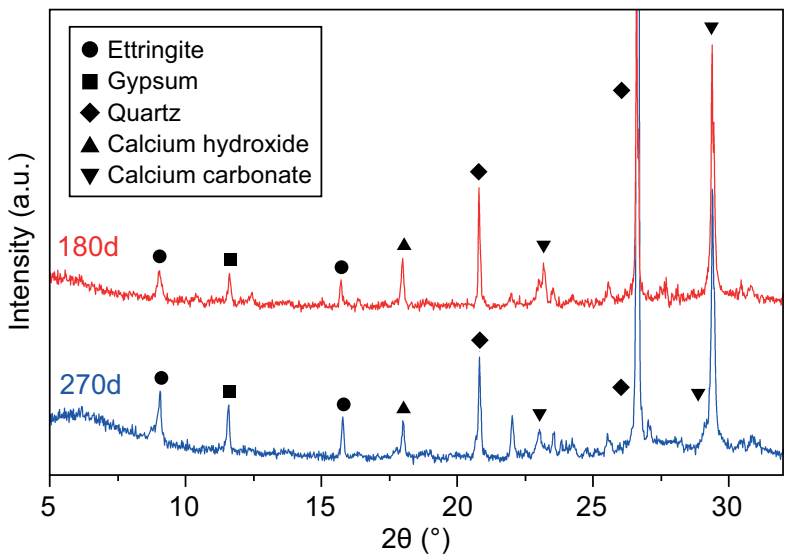

Figure 12. The XRD patterns of F20\%.

\section{Thermal analysis}

Figure 13 presents the TG-DSC curve of the degradation product of F20\% exposed to the sodium sulphate solution subjected to drying-wetting cycles. According to the decomposition temperature corresponding to the heat absorption peak in the DSC curves, the chemical product is identified. Moreover, the weight loss is shown simultaneously in the TG curves. There are three typical endothermic peaks that lie in the ranges $90-110{ }^{\circ} \mathrm{C}$, $130-140{ }^{\circ} \mathrm{C}$, and $430-450{ }^{\circ} \mathrm{C}$. These three temperature stages correspond to the dehydration and decomposition of ettringite, the dehydration and decomposition of gypsum, and the decomposition of calcium hydroxide, respectively $[21,22]$. It is further proved that ettringite and gypsum are the main corrosion products in the concrete.

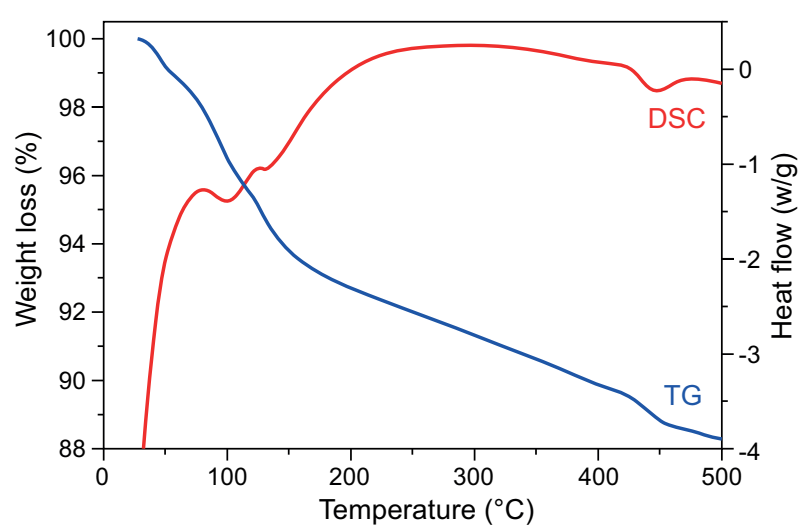

Figure 13. The TG-DSC curves of the deterioration products of F20 \% after 90 days.

\section{CONCLUSIONS}

From the present study, the following major conclusions can be drawn:

- When the different types of concrete exposed to drying-wetting cycles in the sodium sulphate solution, the changing process of the weight loss of concrete can be classified into three stages: a decreased stage, a steady stage and an increased stage. The RDME of the concrete exhibits three distinct periods: a decreased period, a steady period, and an accelerating decreased period. The compressive strength loss of the concrete exhibits the following three periods: an increased period, a decreased period and an accelerating decreased period. The degradation rate of the concrete greatly accelerated after $210 \mathrm{~d}$.

- As the corrosion time grows, the $V_{\mathrm{f}}$ decreases and the $H_{\mathrm{f}}$ of the concrete increases, indicating that the deterioration degree of the concrete increases. There is a significant relationship between the RDME and the $H_{\mathrm{f}}$ of the concrete after $210 \mathrm{~d}$. By measuring the $H_{\mathrm{f}}$ of the concrete, the deterioration degree of the concrete could be effectively estimated.

- The addition of a mineral admixture in the concrete could improve the sulphate resistance property of the concrete when exposed to the simultaneous action of a sulphate attack and drying-wetting cycles. The damage to the concrete decreases with an increase in the fly ash content. However, the sulphate resistance property of the concrete is significantly decreased when the fly ash content reaches $30 \%$. When mixed with $20 \%$ fly ash and $30 \%$ slag, the sulphate resistance property of the concrete is the best.

\section{Acknowledgements}

This project was supported by the Programme for the Changjiang Scholars and Innovative Research Team in the University (IRT13089), the Key Scientific and Technology Project of Henan Province (No. 182102310763, 182102310804) and the Key Scientific Research Projects of Henan University (No. 18A560005). 


\section{REFERENCES}

1. Mullauer W., Beddoe R.E., Heinz D. (2013): Sulfate attack expansion mechanisms. Cement and Concrete Research, 52 208-215. doi:10.1016/j.cemconres.2013.07.005

2. Santhanam M., Cohen M.D., Olek J. (2003): Mechanism of sulfate attack: a fresh look Part 2: proposed mechanisms. Cement and Concrete Research, 33, 341-346. doi:10.1016/ S0008-8846(02)00958-4

3. Bassuoni M.T., Nehdi M.L. (2009): Durability of self-consolidating concrete to sulfate attack under combined cyclic environments and flexural loading. Cement and Concrete Research, 39 (3), 206-226. doi:10.1016/j.cemconres.2008. 12.003

4. Chen Y.J., Gao J.M., Tang L.P., Li X.H. (2016): Resistance of concrete against combined attack of chloride and sulfate under drying-wetting cycles. Construction and Building Materials, 106, 650-658. doi:10.1016/j.conbuildmat.2015. 12.151

5. Gao J.M., Yu Z.X., Song L.G. (2013): Durability of concrete exposed to sulfate attack under flexural loading and dryingwetting cycles. Construction and Building Materials, 39, 33-38. doi:10.1016/j.conbuildmat.2012.05.033

6. Ould Naffa S., Goueygou M., Piwakowski B., Buyle-Bodin F. (2002): Detection of chemical damage in concrete using ultrasound. Ultrasonics, 40, 247-251. doi:10.1016/S0041624X(02)00146-4

7. Wang J.B., Niu D.T., Zhang Y.L. (2015): Mechanical properties, permeability and durability of accelerated shotcrete. Construction and Building Materials, 95, 312-328. doi:10.1016/j.conbuildmat.2015.07.148

8. Wang J.B., Niu D.T. (2016): Influence of freeze-thaw cycles and sulfate corrosion resistance to shotcrete with and without steel fiber. Construction and Building Materials, 122, 628-636. doi:10.1016/j.conbuildmat.2016.06.100

9. Niu D.T., Wang Y.D., Ma R., Wang J.B., Xu S.H. (2015): Experiment study on the failure mechanism of dry-mix shotcrete under the combined actions of sulfate attack and drying-wetting cycles. Construction and Building Materials, 81, 74-80. doi:10.1016/j.conbuildmat.2015.02.007

10. Zhang F., Cai J.J., Li S.C., Niu P.X., Li S.K. (2012): Ultrasonic detection of freeze-thaw damage thickness of concrete. Journal of Shenzhen University Science and Engineering,
29 (3), 207-210. doi:10.3724/SP.J.1249.2012.03207

11. Zhang Y.Q., Yu H.F., Wang J.C. (2009): Study of surface damage rule of concrete structure exposed to salt freezing condition. China Journal of Highway and Transport, 22 (4), 57-63.

12. Skalny J., Marchand J., Odler I. (2002). Sulfate attack on concrete. London and New York. Spon press.

13. Sahmaran M., Erdem T.K., Yaman I.O. (2007): Sulfate resistance of plain and blended cements exposed to wettingdrying and heating cooling environments. Construction and Building Materials, 21, 1771-1778. doi:10.1016/j. conbuildmat.2006.05.012

14. Li G.S. (2012): Sulfate resistance of fly ash concrete. Journal of the Chinese Ceramic Society, 40 (1), 39-48.

15. GB/T 50082-2009 (2009): Standard for test method of long-term performance and durability of ordinary concrete. Chinese Standard Institution press.

16. Jin Z.Q., Sun W., Zhang Y.S. and Jiang J.Y. (2007): Interaction between sulfate and chloride solution attack of concretes with and without fly ash. Cement and Concrete Research, 37, 1223-1232. doi: 10.1016/j.cemconres.2007. 02.016

17. GB/T 50081-2002 (2002): Standard for test method of mechanical properties on ordinary concrete. Chinese Standard Institution press.

18. CECS 21:2000 (2000): Technical specification for inspection of concrete defects by ultrasonic method. China Association for Engineering Construction Standard press.

19. Mehta P. K., Monteiro P. J. (2006): Concrete: microstructure, properties, and materials. New York. Mc Graw Hill press.

20. Zhang F.J., Yuan Y.S., Du J.M. (2011): Ultrasonic detection in concrete structures of damage from sulfate attack. Journal of China University of Mining and Technology, 40 (3), 373-378.

21. Jiang L., Niu D.T., Yuan L.D., Fei Q.N. (2015): Durability of concrete under sulfate attack exposed to freeze-thaw cycles. Cold Regions Science and Technology, 112, 112-117. doi: 10.1016/j.coldregions.2014.12.006

22. Gao R.D., Li Q.B., Zhao S.B. (2013): Concrete deterioration mechanisms under combined sulfate attack and flexural loading. Journal of Materials in Civil Engineering, 25, 39-44. doi:10.1061/(ASCE)MT.1943-5533.0000538 